\title{
ORTHODONTIC TRIAGE AS A MEANS OF REDUCING INAPPROPRIATE REFERRALS
}

\section{MJ Trenouth, Consultant Orthodontist Royal Preston Hospital}

\section{INTRODUCTION}

In the UK the proportion of orthodontists to 12-year-old children is the lowest in Europe ${ }^{(1)}$ (Table 1). Historically this has led to long waiting lists with demand for orthodontic treatment exceeding supply. The situation has been exacerbated by dramatic improvements in dental health, which has also increased demand for treatment.

\begin{tabular}{|ll|lr|}
\hline Country & Ratio & Country & Ratio \\
\hline Norway & $1: 325$ & Finland & $1: 550$ \\
\hline USA & $1: 352$ & Italy & $1: 787$ \\
\hline Denmark & $1: 383$ & Greece & $1: 870$ \\
\hline Sweden & $1: 416$ & Hungary & $1: 1542$ \\
\hline Germany & $1: 427$ & Spain & $1: 1798$ \\
\hline \multicolumn{4}{|c}{ UK 1: 2389 } \\
\hline
\end{tabular}

Table 1 Ratio of Qualified Orthodontists to 12-year-old population

\section{AIMS OF THE AUDIT}

There has traditionally been a division between primary and secondary care. In the UK access to secondary care has been restricted to patients referred from the primary care system. The gate-keeper function of general practitioners is believed to increase the efficiency of the specialist system, but to what extent are patients referred inappropriately? In order to answer this question, an objective measure has now been established in the form of the Index of Orthodontic Treatment Need (IOTN) ${ }^{(2)}$. Patients were placed into one of five grades based on the worst occlusal trait in their malocclusion.

Grade 1 was ideal, no need for treatment

Grade 2 was little need

Grade 3 borderline need

Grade 4 definite need

Grade 5 very great need.

\section{STANDARD TO BE TESTED}

An inappropriate referral was defined by O'Brien $e t a l^{(3)}$, as a patient with a dental health component of IOTN of grade 3 and below. This was taken as the standard to be tested in the present audit.

\section{SCHOOL POPULATION}

In a survey of 333 11-12-year-old children ${ }^{(2)}$, one third on the population falls into grades 4 and 5 (definite need), one third falls into (borderline need) and one third into grades 1 and 2 (little or no need) (Figure 1). On this basis, approximately 33\% of the 12-year-old population would require treatment.
Very similar results were obtained by Holmes ${ }^{(4)}$ in a survey of 955 12-year-old Sheffield school children.

\section{REFERRED POPULATION}

An audit was undertaken to prioritise the 1484 patients on the waiting list at the Royal Preston Hospital according to their treatment need using IOTN.

The distribution of IOTN grades (Figure 2) demonstrates a marked skew towards the higher grades when compared to the school population (Figure 1), which approximates to normal distribution.


Figure 2 Referred population DHI before triage 


\section{TREATED POPULATION}

A previous audit on 70 consecutively finished cases showed a distribution which is even more skewed (Figure 3). This compared favourably with the results of other reported studies using IOTN ${ }^{(5)}$. None of the treated cases fell into grades 1 or 2 and only $10 \%$ into grade 3 , as opposed to the referred cases, where $3.26 \%$ fell into grades 1 and 2 and $20 \%$ in grade 3 . It would appear that the number of cases in grade 3 is reduced by $50 \%$ and those in grades 1 and 2 elimated entirely by orthodontic diagnosis in the hospital. This has the effect of increasing the percentage of patients in grade 4 from $45 \%$ to $54.3 \%$ while the percentage in grade 5 changes slightly i.e. $32 \%$ to $35.7 \%$.

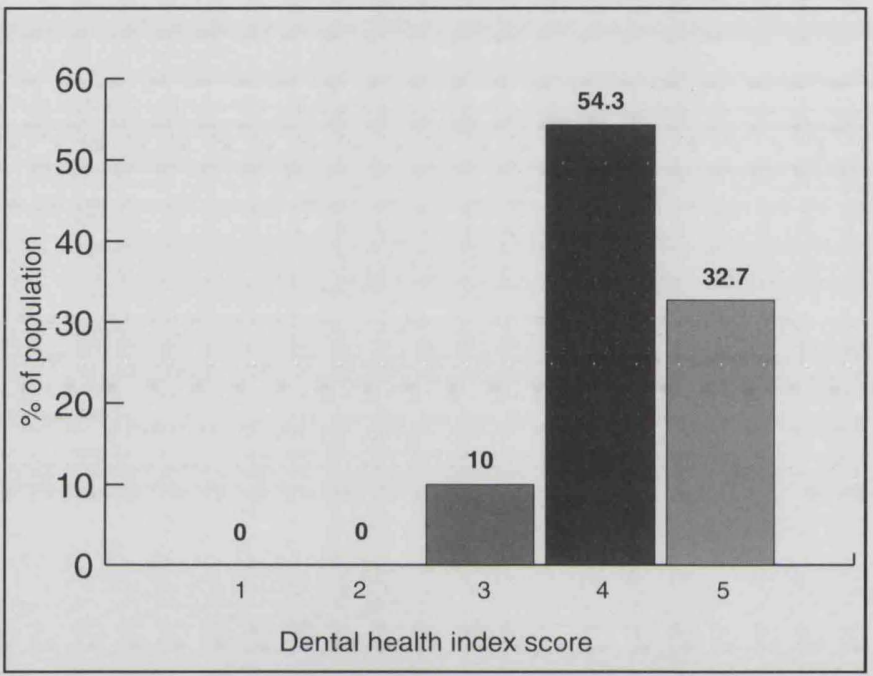

Figure 3 Treated population DHI

\section{THE INTRODUCTION OF TRIAGE}

After prioritisation of the waiting list, a system or orthodontic triage was introduced. All new patients were seen within six weeks and placed on the waiting list according to IOTN. Priority was given to grade 5 .

\section{THE EFFECT OF TRIAGE ON IOTN}

A further audit of 100 consecutively referred patients was performed (Figure 4). The triage system had the effect of reducing the numbers in grade 3 from 20 to $2 \%$ and those in grade 4 from 45 to $38 \%$. The number in grade 5 however, correspondingly rose from 32 to $60 \%$. Patients in grade 1 and 2 were eliminated altogether.

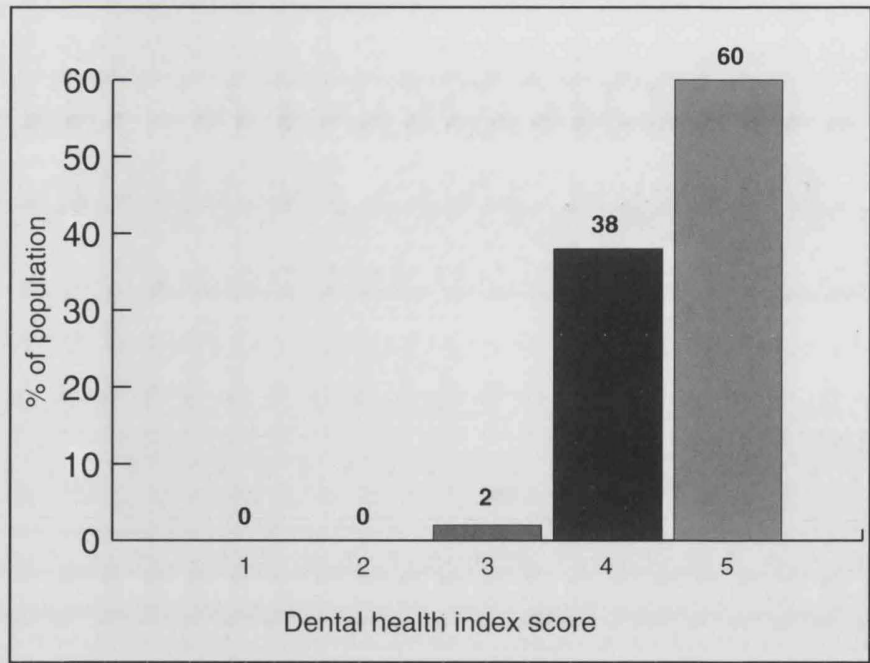

Figure 4 Referred population DHI after triage

The inappropriate referral rate (IOTN grade 3 and below) was therefore reduced from $23.26 \%$ to $2 \%$ by orthodontic triage.

Orthodontic triage seems to be an effective way to reduce inappropriate referrals, unlike referral guidelines, which have been shown to be ineffective in a randomised controlled study ${ }^{(6)}$.

\section{REFERENCES}

1 O'Brien K. The referral of patients for hospital based orthodontic treatment in the North West Region. A report University of Manchester Dental School. 1995

2 Brook PH and Shaw WC The development of an index or orthodontic treatment priority. Eur J Orthodont 1989; 14:125139

3 O'Brien K, McComb JL, Fox N, Bearn D and Wright J Do dentists refer orthodontic patients inappropriately? B Dent J. 1996; 181:132-136

4 Holmes A The prevalence of orthodontic treatment need B J Orthodont 1992; 19:177-182

5 Trenouth MJ An assessment of orthodontic need and treatment standards using occlusal indices. Lancaster and Westmorland Medical Journal. 1994; 2:50-53

6 O'Brien K, Wright J, Conboy F, Bagley L, Lewis D, Read M. Thompson R, Bogues W, Lentin S, Parr G, Aron B The effect of orthodontic referral guidelines: a randomised controlled trial. B Dent J 2000; 188:392-397 